\title{
Some notes on split ergativity in Hittite
}

\author{
Marco Petolicchio
}

Palacký University, Department of Romance Languages, Olomouc, Czech Republic

Received 24 July 2019; Accepted 8 August 2019

Abstract: The Hittite grammar is characterized by a morphosyntactic splitthat affects the behaviour of the inflectional classes of Noun phrases (DPs).
While a singular neuter transitive subject is marked by /-anza/ suffix, commons DPs end with an /-š/ mark. In addition, intransitive neuter
subjects and neuter objects pattern in the same way, marked by /-ø/, while in commons the object role is marked by an/-n/ ending, which
distinguishes it from the subjects. The aim of this paper is to investigate over a possible definition of split ergativity in the Hittite grammar.
Keywords: Hittite •Indo-European languages • morphosyntax • syntax • split-ergativity
(C) Sciendo

\section{Introduction}

Hittite is an extinct language of the Indo-European linguistic family, spoken during XIX-XIII century b.C. in the Anatolian area. The literal production can be grouped in three phases [1]: Old (OH:1570-1450), Middle (MH:1450$1380)$ and New Hittite (NH: 1380-1200). Almost the whole documentation is written on clay tablets in a syllabic cuneiform alphabet [2].

The Hittite grammar exhibits a split in terms of markedness of syntactic arguments (DPs) ${ }^{1}$ on the basis of their morphosyntactic features, which I refer to as "Class" in order to distinguish from gender [5, p. 241]. I adopt the typological conventions for the arguments given by Dixon [6]: $A$ is the transitive subject, $S$ the intransitive and $O$ the object:

- Class I that groups animate/inanimate common gender DPs inflects subjects with no relevance to transitivity and group apart the object, yielding for a $((A=S) \neq 0)$ morphosyntactic realization;

- Class II for inanimate neuters in which objects and intransitive subjects are treated in the same less marked way, apart from subjects of transitive clauses, for which: $(A \neq(S=0))$;

At the bottom of animacy/definiteness/individuation hierarchy appear the terms of the Class II, while at the top take place pronouns, deictic and definite NPs. As well established by Silverstein [9], elements at the bottom of the hierarchy are usually associated with an ergative behavior (ERG), while the ones on the top inflect in accusative system (ACC). Hittite grammar strikes for a similar perspective (Table 1 and 1):

Table 1: Markedness and syntactic roles in Hittite

\begin{tabular}{|c|c|c|c|}
\hline & A & S & 0 \\
\hline Class I & - & - & + \\
\hline Class II & + & - & - \\
\hline
\end{tabular}

(1) Silverstein Hierarchy (1976) and Split alignments

\footnotetext{
${ }^{1}$ The abbreviations respect [3], while the gloss styles adher to the widely recognized Leipzig Glossing Rules [4].

${ }^{2}$ An analysis of the split intransitivity in Hittite goes far beyond the present scope; a great amount of data in [7], [8].
} 


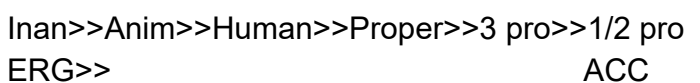

A similar situation is widespreadly known and grounds on evidences raised up by typological studies and linguistic comparison; as noted by Melchert [10], the Hittite shows a pattern that can fit in this hierarchy.

\section{Grammatical properties}

Rizza [5] shows how features such as Class, Gender and Number play a role in syntactical description of Anatolian languages, resulting in an entangled way. At the bottom of definiteness/individuation/animation hierarchy we identify a subset of DPs characterized by inanimate referent and grammatical neuter gender $(\gamma)$, while common gender/ animate nouns are on a upper level $(\alpha)$. In addition, inanimate but common DPs $(\beta)$ grammatically pattern in the same way as common/animate DPs. Giving a first definition of these kinds of grammatical subclasses, we group them as relevant in a grammatical workspace, e.g. resulting in morphosyntactic pattern:

- Class I: common grammatical gender, animate $(\alpha)$ and inanimate $(\beta)$;

- Class II: neuter grammatical gender, $(\gamma)$.

\section{$\phi$-split in Hittite DPs and alignment split}

Usually, terms of Class I are described to inflect accusatively (2a), while Class II results in an ergative alignment $(2 \mathrm{~b}-2 \mathrm{c})^{3}$ :

(2)

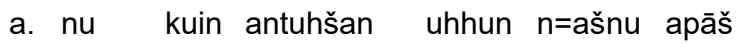

CONN Rel.ACC Man.ACC See.1sg CONN-proClit CONN Dem.NOM.sg

attaš=šiš ešta

Father.NOM.sg=Poss.3s Be.3s

"And the man who I see, which one is his father".

b. nu apat eshar kuwapi paizz[i]

CONN Dem.ABSBlood.ABSwhen Go.3s

"And when the blood goes". (KUB 14.3 IV 52)

c. esharas GIG-an ishananza parkunuzi

Blood.GEN Illness.ACC blood.ERG Purify.3s

"The blood purifies the illness of the blood".

\section{Agreement and control}

Transitive subjects of Class II, that end in /-anzal, and the ones in Class I ending with a /-š/ nominative (NOM) morph are fully equal in terms of subjecthood and no differences arise in terms of control of verbal control and agreement with quantifiers: a transitive subject shares its Number value with the predicate and agrees with a NOM inflected quantifier, e.g. in the demonstratives, while the verbal control knows a split between the behaviour of Class I vs. Class II intransitive subject S:

- Intransitive Class I subjects control verbal agreement in terms of Number feature;

- Intransitive Class II subjects do not control verbal agreement in terms of Number feature, which results in a default 3 sg either with a singular or a plural DP.

3 I will use ERG/ABS notation for the terms of Class II, while NOM/ACC applies to the term of Class I. In literature, the ABS notation corresponds to NOM/ACC.Neuter, while ERG to NOM.Neuter. 
(3)
a. kē ešhār paizzi/*painzi
Dem.ABS.pl Blood.ABS.pl Go.3šg/*3pl
"Those bloods go(es)".
b. kī/*kāš ešhar paizzi
Dem.ABS.sg/*ERG.sg Blood.ABS.sg Go.3sg
"This blood goes".
c. kē išhanantes zik wemiyanzi/*wemiyazzi
Dem.ERG.pl Blood.ERG.pl You.ACC-DAT Reach.3pl/*3sg
"Those bloods will reach you".
d. kē/*kūš attieš zik wemiyanzi/*wemiyazzi
Dem.NOM.pl/*ACC.pl Father.NOM.pl You.ACC Reach.3pl/*3sg
"Those fathers will reach you".
e. kē/*kūš attieš painzi/*aizzi
Dem.NOM.pl ${ }^{*} A C C$.pl Father.NOM.pl Go.3pl/*3sg
"Those fathers go".

\section{$\bar{A}$-movement and case}

A-bar movements of DPs, so the elements that undergo movement in a position in the Left Periphery of the sentence [11], are comparable between the terms in the two classes. The following examples show wh effects in Hittite, for which neuters and commons wh phrases undergo the same structural relationship with the other elements in the clause (4a-4b). For the sake of clarity: (i) Hittite allows wh-in situ [12] and (ii) clitic pronouns do not express A-function, and are limited to $S$ and $O$ functions [7]:

( 4 )
a. kuiš -war -aš $\quad$-kan kuenta
who.NOM.sg -QUOT -them.ACC -ptc kill-3sg.pret
"Who killed them?" (KBo III 67 ii 4)
b. kuit -ta memahhi
what.ABS -you-sg.dat say-1sg.pres
"What can I say to you?" (KBo XXVI 65 iv 23, 25)

\section{Discussion}

The given examples focus on the following:

\section{( 5 )}

a. Class II DPs in A function are equal to those of Class I in syntactic terms;

b. Class II appears to be more marked in A-function;

c. Class I appears to be more marked in O-function;

d. S-function is the less marked, when it patterns with either O (Class II) or A (Class I);

e. Movements of the DPs to the Left Periphery are fully comparable and they are allowed limitless for DPs core case marked, e.g. ergative can be extracted (relativized, questioned ecc.);

f. Class I DPs in S share their [Number] feature value with the verb, while Class II DPs in S do not trigger verbal agreement, which results in default 3 sg., also with plural Class II subjects $\mathrm{S}$. 
As we have seen, in ergative languages a DP ERG cannot be moved in $\bar{A}$ position ${ }^{4}$, while Hittite shows a fully symmetric behaviour of NOM and ERG in these terms. On the other side, a morphological analysis of the noun declension seems to be understandable in an ergative pattern.

I propose that this kind of split is morphologically motivated, resulting in a split system which involves the $v$ Head, that overtly marks the externally merged DP in its specifier. Note that $v$ is not responsible for case assignment of this DP, which has to agree to T for (somewhat as) EPP/Nominative case checking.

In order to achieve a first explanation of the Hittite data, I would assume a synchronic perspective to these facts. For doing this, I will ground on the Minimalist assumptions (latu sensu) about the architecture of language.

Recalling the Hittite nominal declension, we can distinguish two core cases (NOM, ACC), a NULL value for case (ABS) and somewhat unclear between derivational/inflectional (ERG). The status of the "ergative" anzalantes[pl] ending is one of the most prominent debate around Hittite grammar: if it is all internal to lexicon we are in a derivational morphology area [16], [17], while if it is syntactically motivated we are fronting with a true split ergative system [10], [18]. Other relevant studies [5, 19-21] are somewhat in the middle between the two hypotheses. The aim of the sequent section is to explain Hittite split as a Feature driven split, totally in syntactic workspace.

For the sake of clarity, I would like to address here the question: ant-s is a synchronically motivated formation for neuter nouns, distinct from thematized nouns in ant of common class nouns in which this morph act for an individualizing feature internally to the lexicon; ant-(e)-s resemble so nearly an ERG case marker because it is spelled as somewhat as a portmanteaux morpheme. Despite this, I will show that we cannot escape from an accusative syntactic alignment.

\section{Framework}

A transitive finite clause is usually represented by four phrases projected by their heads [22], which correspond (in reverse ordering) to $\mathrm{C}$ (omplementizer) - $\mathrm{T}$ (ense) - $\mathrm{v}($ Little verb) - $\mathrm{V}(\mathrm{erb})$, where the so signed " $\mathrm{v}$ " ph(r)ase is associated with the verbal transitivity/ hosts base generation of external arguments.

A Lexical Item (LI) is somewhat a bundle/set of features: some features are phonological, some logical/semantic and others formal/syntactic: $\mathrm{LI}=[\mathrm{P}, \mathrm{L}, \mathrm{S}]$.

When an LI enters in the course of the derivation, it has some features which need to be dismissed in syntax, resulting in a legible output to the interfaces (Sensory-Motor for PF and Conceptual-Interpretative for LF): interfaces are not able to handle with syntactic items, and a syntactic derivation must result in an interpretable way. Assume two items, e.g. a noun (D) that carries a set of features, for example a necessity for Case feature to be dismissed/ checked. This LI acts as a Goal, so it is active for Feature matching with a Probe - an head that is in some structural relationship with the Goal (c-command) and that presents the same feature. Assuming that $D$ has a generic feature $F$ not yet checked: a Probe $X$ has the same feature with some value, sadly $X$. Identity of features assure us of the matching. While the value of the one is copied as the value of the other, matching resolves into an agreement between features (for simplicity I show Agree and Movement, despite it is necessary or not for agree to be driven by other requirements):

\section{(6)}
a. $\mathrm{X}[\mathrm{F}: \mathrm{X}] \ldots \mathrm{D}[\mathrm{F}:-]$
b. $\mathrm{D}[\mathrm{F}: \mathrm{X}] \ldots \mathrm{X}[\mathrm{F}]$
c. $\mathrm{D}[\mathrm{F}]$

At this stage of the derivation the features are checked, so they are inaccessible to further computation and are interpretable by the interfaces.

\footnotetext{
$4 \quad$ I will not provide here for an explanation of this asymmetry between languages. For a theoretically-set point of view cfr. [13]-[15]. Also, while ergative languages can generally display A-bar movement of ERG arguments only if ABS moves first (so, D checks Case), some others freely allow DPerg extractions; however I do not discuss it further.
} 


\section{v-head and /-ant-/ morpheme}

Neuters in A-function show -ant-s ending and control verbal agreement in $\mathrm{T}$; the same is for common nouns that show only -š ending.

In this analysis, I argue that /ant-/ is a morphological realization of the matching established by two features carried in syntax by a head $\mathrm{D}$ and $\mathrm{v}$ in a local configuration, while the NOM case is checked under c-command by the probe $T$ to the goal which is in the Specifier of the lower phrase. While a common DP (Class I) does not show a morphological marker for v-D configuration, neuter DPs (Class II) realize it as /ant-/. Then, common and neuter DPs externally merged in Spec, vP check their case feature against the T head, which results in NOM ending. Then they raise to Spec,TP and $\phi$ agreement with T is established (7):

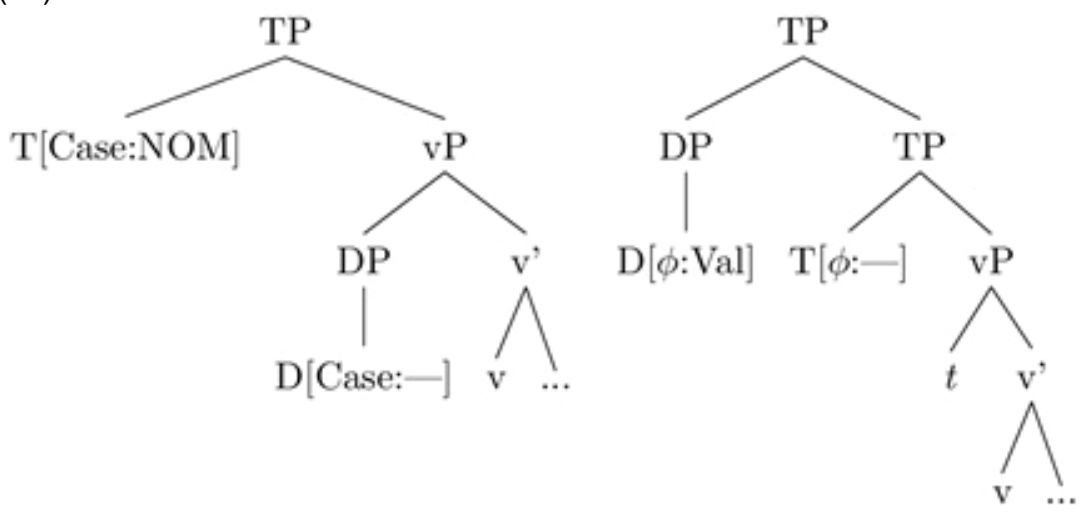

\section{Intransitive clauses}

Intransitive clauses (put aside the question about a definition of split intransitivity in Hittite) do not exhibit the " $v$ phrase", for which -ant- suffixation cannot be made. While a common DP that raises to Spec, TP controls verbal agreement, a neuter cannot. Features between $T$ and a neuter $D$ result in a default agreement [3sg], either with singular or plural subjects:

( 8$)$

a. ta- -an anda 3-is LUGAL-us SAL.LUGAL-ass- -a

CONN 3SG-ACC into three-times king.NOM queen.NOM and

zeriya allapahhanzi

Bowl.DIR Spit.PRES.3PL

"The king and the queen spit three times inside, into the bowl". (StBoT 8 iv 34-35)

b. nu- -zza DUMU.NITAMES karti- -smi piran memir

CONN PTC boy.PL heart.D/L 3PL.POSS.D/L before speak.PRET.3PL

"The boys said to themselves". (StBoT 17, obv. 14)

(9)

a. Askalima uddār arais

Askaliya.ALL.sg Things.ABS.pl Turn.PRET.3sg

"The things turned against Askaliya". (KBo III 34 ii 18)

b. ginuwa- -nnas kan katkattiskizzi

Knee.ABS.PI 1PI.DAT ADV Trumble.3sg

"Our knees trumble". (KUB 33.103 III 4) 
In this sense the absence of the $v$ head could be linked to the absence of a NOM ending to neuter DPs in intransitive clauses, while common DPs in Spec, TP show overtly morphological case realization as NOM. We can refer to this behaviour of neuter as a NULL case or ABS, opposed to the marked ERG.

\section{Conclusion}

In this article, I tried to show how the Hittite syntax is accusative in terms of argument extraction and verbal control. Also, a split between the Classes of the DPs drive syntax in different manners. At the low end of the animacy/definiteness scale items show a marked realization for A-function, which is an overtly realization of v-D T-D agreement, while $v-D$ feature matching for $D$ of Class I does not result in a morphological way. In addition, Intransitive sentences lack $v$ and a neuter $D$ has an unvalued feature, which result in a default agreement or no overt morphological case.

Table 2: Syntactic roles and morphological realization in Hittite

\begin{tabular}{|c|c|c|c|c|}
\hline & \multicolumn{2}{|c|}{ A } & S & O \\
\cline { 2 - 5 } & $\vee$ & T[Case] & T[Case] & $v[$ Case] \\
\hline Class I & $-\varnothing-$ & $-\check{s}$ & $-s$ & $-n$ \\
\hline Class II & -ant- & $-\check{s}$ & $-\varnothing$ & $-\varnothing$ \\
\hline
\end{tabular}

The exact status of the role of the feature involved in the $v$ head cannot be deepened here and this is a matter for future researches, as than the default agreement for intransitive verb/DPneuter and the evolution of the system in diachrony. In addition, a similar picture seems to accord with Hittite data that resemble an accusative syntax coherently shown by Class I DP in morphological terms, while Neuters fail into check something in the set of $\phi$ which fail in the derivation to check (overtly) ACC in v and NOM in T.

The suffixation in -ant- for neuter nouns is syntactic and it is not internal to the Lexicon, and depends on syntactic context, in transitive sentences. Despite some analyses of the phenomenon, I argue that T-case is NOM, v-case is ACC and $\phi$ features play a role in syntactic workspace: while a Dneuter cannot check them with $v$, it remains defective and cannot show NOM case ending but NULL, as in intransitive clauses.

\section{References}

[1] R. Francia, Lineamenti di grammatica ittita. Edizioni Scripta Manent, 2012.

[2] H. A. Hoffner and H. C. Melchert, A grammar of the hittite language, vol. 1 \& 2. Eisenbrauns, 2008.

[3] C. Boeckx, "List of abbreviations and symbols," in The oxford handbook of linguistic minimalism, C. Boeckx, Ed. Oxford University Press, 2012, pp. xv$x x$.

[4] B. Comrie, M. Haspelmath, and B. Bickel, "The leipzig glossing rules: Conventions for interlinear morpheme-by-morpheme glosses," 2008.

[5] A. Rizza, "Ipotesi su problemi di genere, numero ed ergatività in eteo," Atti del sodalizio glottologico milanese, vol. 2012, no. 7 ns, 2013.

[6] R. M. Dixon and S. R. Anderson, Ergativity. Cambridge University Press, 1994.

[7] A. Garrett, "Wackernagel's law and unaccusativity in hittite," Stanford: CSLI Publications, 1997, pp. 85-103.
[8] S. Luraghi, "Transitivity, intransitivity and diathesis in hittite," Индоевропейское языкознание и классическая фрилология, nos. 14-2, pp. 133154, 2010.

[9] M. Silverstein, "Hierarchy of features and ergativity," Grammatical categories in Australian languages, pp. 112-171, 1976.

[10] H. C. Melchert, "The problem of the ergative case in hittite," Grammatical case in the languages of the Middle East and Europe, p. 161, 2011.

[11] L. Rizzi, "The fine structure of the left periphery," in Elements of grammar, Springer, 1997, pp. 281337.

[12] M. G. C. Huggard, "Wh-words in hittite: A study in syntax-semantics and syntax-phonology interfaces." PhD thesis, UCLA, 2015.

[13] J. Bobaljik, "On ergativity and ergative unergatives," MIT Working papers in Linguistics, vol. 19, no. 4588, p. 334385, 1993. 
[14] K. G. Murasugi, "Crossing and nested paths-np movement in accusative and ergative languages," PhD thesis, Massachusetts Institute of Technology, 1992.

[15] A. Assmann, D. Georgi, F. Heck, G. Müller, and P. Weisser, "Ergatives move too early: On an instance of opacity in syntax," Syntax, vol. 18, no. 4, pp. 343-387, 2015.

[16] É. Benveniste, Hittite et indo-européen: études comparatives, vol. 5. Adrien Maisonneuve, 1962.

[17] S. Patri, L'alignement syntaxique dans les langues indo-européennes d'Anatolie. Otto Harrassowitz Verlag, 2007.
[18] A. Garrett, "The origin of np split ergativity", Language, vol. 66, no. 2, pp. 261-96, 1990.

[19] E. Laroche, Un" ergatif" en indo-européen d'Asie mineure. Klincksieck, 1962.

[20] P. Dardano, "L'allineamento sintattico delle lingue indoeuropee dell'Anatolia: Vecchi problemi e nuove proposte alla luce di una recente pubblicazione." JSTOR, 2013.

[21] P. Goedegebuure, "Split-ergativity in hittite," Zeitschrift für Assyriologie und vorderasiatische Archäologie, vol. 102, no. 2, pp. 270-303, 2013.

[22] N. Chomsky, The minimalist program. MIT Press, 1995. 